\title{
Comparing image-based point clouds and airborne laser scanning data for estimating forest heights
}

\author{
Sami Ullah ${ }^{(1)}$, \\ Petra Adler ${ }^{(2)}$, \\ Matthias Dees ${ }^{(1)}$, \\ Pawan Datta ${ }^{(1)}$, \\ Holger Weinacker ${ }^{(1)}$, \\ Barbara Koch ${ }^{(1)}$
}

\begin{abstract}
Accurate and updated knowledge of forest tree heights is fundamental in the context of forest management. However, measuring canopy height over large forest areas using traditional inventory techniques is laborious, time-consuming and excessively expensive. In this study, image-based point clouds produced from stereo aerial photographs (AP) were used to estimate forest height, and compared to Airborne Laser Scanning (ALS) data. We generated image-based Canopy Height Models (CHM) using different image-matching algorithms (SGM: Semi-Global Matching; eATE: enhanced Automatic Terrain Extraction), which were compared with a pure ALS-derived CHM. Additionally, plotlevel height and density metrics were extracted from CHMs and used as explanatory variables for predicting the Lorey's mean height $(L M H)$, which was measured at 296 reference points on the ground. $\mathrm{CHM}_{\mathrm{SGM}}$ and $\mathrm{CHM}_{\mathrm{ALS}}$ showed similar results in predicting $L M H$ at sample plot locations (RMSE\% $=8.54$ vs.

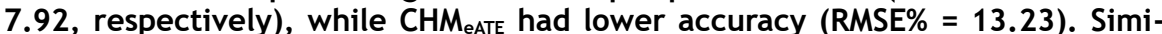
larly, $\mathrm{CHM}_{\mathrm{SGM}}$ showed a lower normalized median absolute deviation (NMAD) from $\mathrm{CHM}_{\mathrm{ALS}}(0.68 \mathrm{~m})$ compared to $\mathrm{CHM}_{\text {eATE }}(1.1 \mathrm{~m})$. Our study revealed that image-based point clouds using SGM in the presence of high-resolution ALSderived digital terrain model (DTM) provide comparable results with ALS data, while the performance of image-based point clouds using eATE is poorer than ALS for forest height estimation. The findings of this study provide a viable and cost-effective option for assessing height-related forest structural parameters. The proposed methodology can be usefully applied in all those countries where AP are updated on a regular basis and pre-existing historical ALS-derived DTMs are available.
\end{abstract}

Keywords: Forest Inventory, Canopy Height Model, Stereo Aerial Photographs, LiDAR, Semi-Global Matching (SGM), enhanced Automatic Terrain Extraction (eATE) change detection, canopy gap dynamic, and single tree detection (Pitkänen et al. 2004, Yu et al. 2004, Koch et al. 2006, Zielewska-Büttner et al. 2016). Height and density metrics derived from $\mathrm{CHMs}$ at plot level can be used for the assessment of forest height, forest timber volume, biomass, basal area and mean diameter-at-breastheight point $(\mathrm{DBH})$ using the area-based approach (ABA - Bohlin et al. 2012, Naesset 2004, Ota et al. 2015, Rahlf et al. 2014, Straub et al. 2013a, White et al. 2013). The same parameters at single tree level can
(1) Chair of Remote Sensing and Landscape Information System, Institute of Forest Sciences, Faculty of Environment and Natural Resources, University of Freiburg (Germany); (2) Forest Research Institute, Baden-Württemberg - FVA (Germany)

@ Sami Ullah (samidawar@gmail.com)

Received: Apr 06, 2016 - Accepted: Oct 30, 2016

Citation: Ullah S, Adler P, Dees M, Datta P, Weinacker H, Koch B (2017). Comparing imagebased point clouds and airborne laser scanning data for estimating forest heights. iForest 10 : 273-280. - doi: 10.3832/ifor2077-009 [online 2017-02-23]

Communicated by: Matteo Garbarino also be derived directly (i.e., tree height and crown area) or indirectly (i.e., volume, basal area and mean $\mathrm{DBH}$ ) from CHM by separation of individual crown using the individual tree detection approach (ITD Brandtberg 1999, Hyyppä \& Inkinen 1999, Koch et al. 2006). CHM as well as height metrics derived from Airborne Laser Scanning (ALS), also called Light detection and ranging (LiDAR) data, were successfully applied in many case studies for the assessment of forest structure information, as ALS has the capability for extraction of both the digital terrain model (DTM), which represents the forest floor, and the digital elevation model (DEM), which represents the entire canopy of forest (Nelson et al. 1984, Nilsson 1996, Hyyppä et al. 2008, Packalén et al. 2008, Tesfamichael et al. 2010, White et al. 2015a, Yamamoto et al. 2017).

Over the last decade, ALS has revolutionized the process of forest mapping and has been used operationally for forest inventory in many Nordic countries like Norway, Finland, and Sweden (Maltamo \& Packalen 2014, Naesset 2007, 2014). However, in many countries, ALS acquisitions are often not as frequently updated as digital stereo 


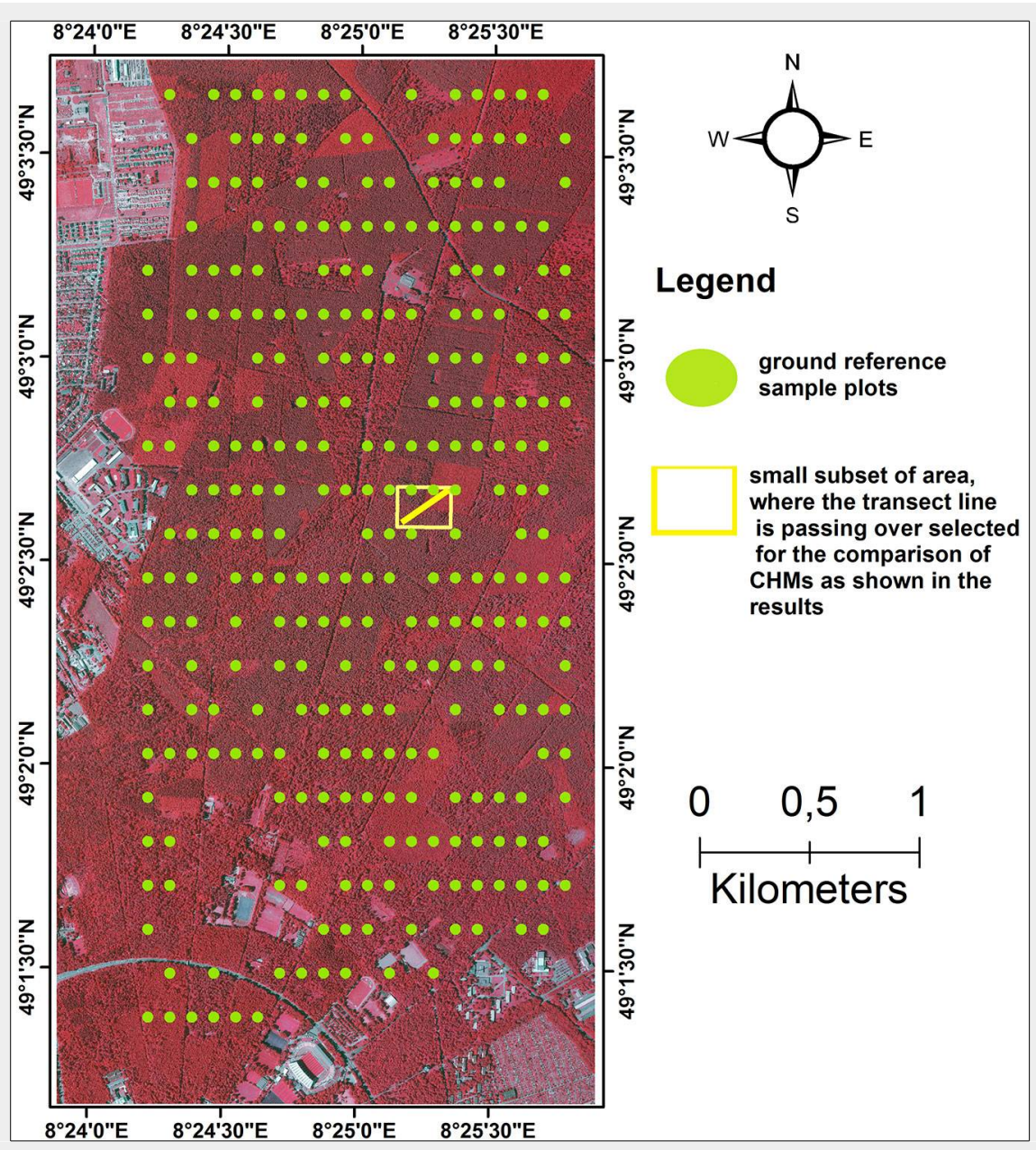

Fig. 1 - Geographical location of the study site. The green points represents the location of the reference sample plots on the ground, while the yellow rectangular block delineates the small subset area where a transect (yellow line) was drawn for visual comparison of the CHMs. Orthophoto and aerial photos: $\odot$ Landesamt für Geoinformation und Landentwicklung für Baden-Württemberg (http://www.lgl-bw.de) Az.: 2851.9$1 / 3$.

aerial photographs (AP) by the survey administrations, and therefore cannot be used for the regular measurement as needed for forest management planning due to high cost. It is also unclear in most federa states in Germany, the time frequency of ALS data acquisition (Dees et al. 2012). APs are updated on a routine basis at regular time intervals by the survey agencies/administration (Straub et al. 2013a, Stepper et al. 2015, White et al. 2015b). As an example in the Baden-Württemberg state of Germany, APs are regularly updated every three years by the Landesamt für Geoinformation und Landentwicklung ( $L G L$ ) and can be used for the regular update of forest structure information, while ALS acquisitions are not that consistent over time. Since ALS data is considered more accu rate, we have used it as one of the reference datasets in our study to estimate forest heights, despite its high costs.

Automatic process of AP based on image matching algorithms can provide sufficiently dense and highly accurate imagebased 3D point clouds for the generation of DSM, but the generation of DTM in dense forest environment, where forest floor is not visible is challenging (White et al. 2013). Hence, the limiting factor of the image-based point clouds is the vertical penetration, which is provided by ALS. Thus the idea of combining photogrammetric image-based DSM with pre-existing historical ALS DTM could be a promising solution for the generation of CHM (Rönnholm et al. 2004, St-Onge et al. 2004, Jan 2005, Véga \& St-Onge 2008, Bohlin et al. 2012).

With the recent advancements of modern stereo photogrammetry, one of the most active research areas in computer vision for 3D mapping is stereo image matching (Scharstein \& Szeliski 2002). There are several software packages and image matching algorithms for the generation of 3D point clouds. For our study, we have selected two widely used programs that are based on different methodological approaches. One is enhanced Automatic Terrain Extraction (eATE): an ERDAS LPS module, that is a normalized correlation area based search windows approach for the identification of corresponding pixels using spatial correlation metrics. The search range along the epipolar line is constrained by estimated minimum and maximum elevation values (Straub et al. 2013b). The second one is Semi-Global Matching (SGM) developed by Hirschmüller (2005, 2008). It uses a pixel-wise approach, utilizing the radiometric robust mutual information and a smoothness constraint to generate dense surface point clouds. The method first identifies a pixel on the base image and then seeks for the similar pixel along the epipolar line in the pair image. The minimum aggregated cost leads to a disparity map. Several studies showed that SGM is the superior methodology (Hirschmuller 2005, Gehrke et al. 2010, Rothermel \& Haala 2011). So far, comparative studies between the point clouds image matching algorithms have not focused over forest terrain, and this forms the main research gap for our study. Our specific goals were: (a) to assess the performance of the images-based point clouds in comparison with ALS for estimating forest heights; (b) to identify which of the two widely used image matching algorithms, namely SGM and eATE, is best suited for forest height retrieval.

\section{Material and methods}

\section{Study area and field data}

The study area is located in a relatively flat area north of Karlsruhe in the Federal State of Baden-Württemberg, Germany, extending from $49^{\circ} 03^{\prime} 37.302^{\prime \prime} \mathrm{N}$ and $08^{\circ}$ $24^{\prime} 02.846^{\prime \prime} \mathrm{E}$ to $49^{\circ} 01^{\prime} 18.773^{\prime \prime} \mathrm{N}$ and $08^{\circ}$ $25^{\prime} 49.981^{\prime \prime}$ E (Fig. 1). The total area covers $12 \mathrm{~km}^{2}$ and the dominant forest tree species are Scots pine (Pinus sylvestris L.), European/Common beech (Fagus sylvatica L.), Sessile oak (Quercus petraea leibel.) and Red oak (Quercus rubra L.). Further tree species including Douglas fir (Pseudotsuga menziesii), Norway spruces (Picea abies) and European larch (Larix decidua) can also occur occasionally.

The state forest service of Baden-Württemberg set up a total of 296 permanent circular concentric plots during the summers of 2006 and 2007 over the entire study area, and these have been used for the collection of ground reference data (Fig. 1). The sample plots were distributed systematically over the study area in a 100 $\times 200 \mathrm{~m}$ sample grid. On each plot, trees with diameter-at-breast-height (DBH) $<10$ $\mathrm{cm}$, between 10 and $15 \mathrm{~cm}$, between 15 and 30 and $>30 \mathrm{~cm}$ were measured, if they were exactly at the distance of 2, 3, 6 and $12 \mathrm{~m}$ from the plot center. Two dominant heights of each main tree species and one dominant height of other mixed species were measured. The remaining tree heights were predicted by species-specific stand height curves developed by the Forest Research Institute, Baden-Württemberg (FVA), Germany (Kublin 2003). Finally, ground Lorey's mean height (LMH) was calculated by multiplying the tree height $(h)$ by its basal area $(\mathrm{g})$, and then the sum of 
the multiplication of individual heights and basal areas are divided by the sum of the plot basal area (Lorey 1878 - eqn. 1):

$$
L M H=\frac{\sum g \cdot h}{\sum g}
$$

where $L M H$ is the ground Lorey's mean height, $g$ is the basal area and $h$ is the tree height. We selected $\mathrm{LMH}$ since it is a standard forest measure to characterize forest canopy height, giving higher weights to trees with a larger basal area.

\section{Remote sensing data}

Full-waveform ALS data was acquired in 2009 by Milan Geoservice Gmbh using the IGL Litemapper 5600 system with a Riegl LMS-Q560 (240 kHz) scanner. For the summer 2009 acquisitions during leaf-on conditions, the study area was flown over twice to obtain a high point density. The first flight was conducted in north-south and the second in the east-west direction. The details of the flight and system parameters of ALS are shown in Tab. 1.

Similarly, we used a block of 28 APs with four spectral bands (blue, green, red and near-infrared). The APs were acquired in summer 2009 during the leaf-on canopy conditions. The aero-triangulation was done by Landesamt für Geoinformation und Landentwicklung (LGL) with ground control points and based on initial measurement by Global Navigation Satellite System (GNSS) and inertial measurement unit (IMU) (LGL). For the projection of the generated datasets, DHDN/3 Gauss-Krüger coordinate system was used throughout the process. More details about the technical parameters are given in Tab. 2 .

Generation of image-based point clouds using enhance Automatic Terrain Extraction (eATE) and Semi-Global Matching (SGM)

Image-based point clouds were generated from AP using eATE manager (integrated module in the LPS ERDAS IMAGINE 2015) by choosing a point sampling density of 1 , whereby every other pixel is matched. A point sampling density of zero might be useful in term of accuracy, but it takes a considerable longer period to be processed (ERDAS_IMAGINE 2012), and hence was not used. A pixel block size of 100 was selected where eATE engine divides the images into blocks of pixels and processes each block separately. Thread 2 indicates the number of distributed processing threads for this eATE process and each thread is assigned to a separate core in the machine. The radiometry threshold defines the measurement (percentage) of contrast around the central pixel in the master image. The default is 2.5 , and it is recommended to use larger (than 2.5) threshold for high contrast images, thereby ensuring a higher possibility of getting good correlated points. For low-contrast images, it is recommended to use a smaller threshold so that eATE correlates more points re- gardless of the contrast. If the threshold is set to zero then all points will be matched (ERDAS_IMAGINE 2012). For segmentation, we used the infrared band because of its higher sensitivity to vegetation compared to the other bands. During the correlation process, we optimized the matching by using all available spectral bands. For window size, which is representative of the pixel area used for computing the correlation coefficient between left and right images, we chose a larger $(15 \times 15)$ value. While the default value is $9 \times 9$, it is recommended to use a larger window size for areas with minimal variation (right in our case) and a smaller window (e.g., $5 \times 5)$ for areas with greater topographic relief. Coefficient start and end indicates the correlation coefficient used for each pyramid level. Higher coefficients range (0.7-0.8) produces higher accuracies, but fewer points may be matched, while a lower range increases the number of correlated points. The search window is the maximum search size in pixels surrounding the point to be interpolated and has a square shape. The default value is 50; a higher number is suitable for low contrast areas, while a lower number is recommended for areas with higher contrast. We use a higher value because it gives better points despite increasing the processing time. A low value may give more uniformly distributed points, but the points may not be accurate. Standard deviation tolerance indicated the tolerance (in meters) for determining the standard deviation of the planar fit (default $=3$ ) and LSQ refinement indicated the pyramid level to apply a least squares refinement. Edge contrast represents the number of pyramid levels to apply edge constraint, and tolerance means the measure in pixel used to accept or reject the point during reverse matching. Smoothing looks for spikes in elevation, and low smoothing option ensures a minimal smoothing for data with few anomalies (ERDAS IMAGINE 2012).

Similarly, image-based point clouds were generated from AP using SGM XPro (integrated in LPS ERDAS IMAGINE 2015) by setting urban situation to zero, as it can be applied to urban areas. We selected Keep vertical which retains point clouds on the vertical surfaces like trees tops.

\section{Generation of Digital Surface Model} (DSM) and Digital Terrain Model (DTM)

DSMs with a spatial resolution of $1 \mathrm{~m}$ were calculated from the image-based point clouds using eATE (DSM eATE$_{\text {AT }}$ and SGM $\left(D_{S M} M_{S G M}\right)$. Similarly, DSM $M_{A L S}$ and DTM were generated from ALS data. For the generation of DSMs and DTMs the active filtering and interpolation techniques as implemented in the TreesVis software (Weinacker et al. 2004) were used. In TreesVis, the generation of DSM and DTM from point clouds is done by using an "ACtive Surface Filtering Algorithm". Before starting the iterative process, the algo-
Tab. 1 - Details of flight and system parameters of Airborne Laser Scanning (ALS).

\begin{tabular}{lc}
\hline Parameters & Value \\
\hline $\begin{array}{l}\text { Flying height [m] } \\
\text { (above ground level) }\end{array}$ & 600 \\
\hline $\begin{array}{l}\text { Field of view [deg] } \\
\text { (full scan angle) }\end{array}$ & 60 \\
\hline Strip width [m] & 520 \\
\hline Measurement rate [kHz] & 240 \\
\hline Point density [points & $-2]$ \\
\hline Flying velocity $\left[\mathrm{m} \mathrm{s}^{-1}\right]$ & $\sim 22$ \\
\hline
\end{tabular}

rithm created three surfaces: the "active surface, a "punch surface" and a "mask surface". The active surface is only allowed to move vertically up and down. Moreover, the active surface represents the desired output, whether DSM or DTM is to be generated. In the case of DTM generation, the active surface is placed lower than the punch surface and move upward, while in the case of DSM generation the active surface is placed above the punch surface and move downward. Each pixel of the punch surface is filled with height values of the lowest 3D point for the calculation of DTM. Similarly, the highest 3D point is chosen as a height for the punch surface for the calculation of DSM within pre-defined pixel size spatial resolution. The mask surface is automatically filled with special flags, necessary for the regulation of minimization process. After creation of these surfaces, the original 3D point clouds were no longer needed for minimization and could be deleted. However, for visualization purposes, the point clouds are still present in the random access memory (RAM) of the computer. The developed active algorithm was up to now only allowed to move up and down, which simplified the process to a great extent. The reason for the movement and deformation of active surface are two types of forces, i.e., the inner forces and the outer forces. The iterative process continues until these forces reach the level of equilibrium. The inner forces

Tab. 2 - Details of flight and technical characteristics of Digital Stereo Aerial Images.

\begin{tabular}{|c|c|}
\hline Details & $\begin{array}{l}\text { Stereo aerial } \\
\text { photographs } \\
\text { /images (AP) }\end{array}$ \\
\hline Camera & UltraCamXP \\
\hline Flying height & $2950 \mathrm{~m}$ \\
\hline Image overlap & $60 \%$ \& $30 \%$ \\
\hline Swat width & $520 \mathrm{~m}$ \\
\hline Acquisition date & Summer 2009 \\
\hline $\begin{array}{l}\text { No. of images used } \\
\text { in a block }\end{array}$ & 28 \\
\hline Spectral bands & $\begin{array}{l}\text { blue, green, red } \\
\text { and near-infrared }\end{array}$ \\
\hline Resolution (GSD) & $0.2 \mathrm{~m}(20 \mathrm{~cm})$ \\
\hline
\end{tabular}



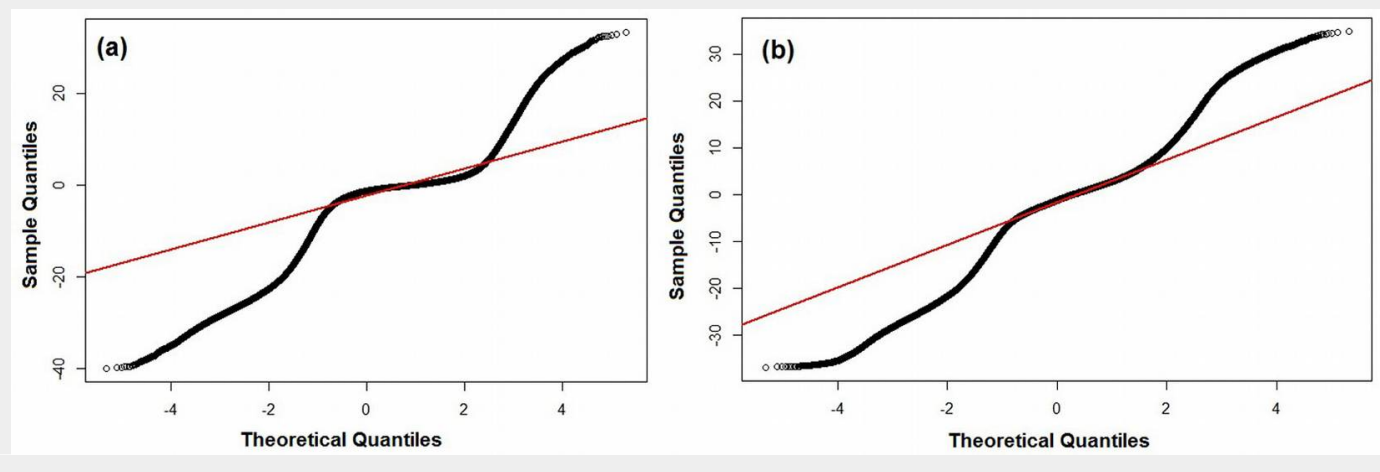

Fig. 2 - Non-normal Q-Q plots of error distributions for CHM difference maps of forested areas. The red lines represent the expected normal distribution.
(a) $\mathrm{CHM}_{\mathrm{SGM}}-\mathrm{CHM}_{\mathrm{ALS}}$

(b) $\mathrm{CHM}_{\mathrm{eATE}}-\mathrm{CHM}_{\mathrm{ALS}}$

introduce stiffness in the active surface in such a way that it will not touch each detail of the punch surface. Each pixel of the active surface is influenced by the expansion, which is defined by the distance to the eight neighboring pixels. The outer forces attract the active surface, which brings deformity in the active surface. The relation between the inner and outer forces defined the degree of deformity. Two different forces are used as outer forces, i.e., a "pressure force" which pushes the active surface downward in case of DTM generation and upward in case of DSM generation. The second outer force is the magnetic ones, where each pixel of the punch surface is attracting the active surface toward itself. The magnetic force is always positive. The iteration process will stop until the vertical movement is lower than a pre-defined threshold. The uncritical pre-defined threshold was set to 0.01 [m], which is better than the vertical measurement accuracy of the given 3D points.

Calculation of Canopy Height Models (CHMs) and computation of explanatory variables (metrics)

We generated three kinds of canopy height models: (1) $\mathrm{CHM}_{\mathrm{SGM}}$ by subtraction of DTM $M_{\text {ALS }}$ from DSM $M_{S G M}$; (2) CHM CATE $_{\text {eA }}$ by subtraction of DTM ALS $_{\text {from DSM }}$ eATE; and (3) $\mathrm{CHM}_{\mathrm{ALS}}$ by subtraction of $\mathrm{DTM}_{\mathrm{ALS}}$ from DSM $_{\text {ALS. }}$.

The most commonly used ALS and imagebased derived metrics from $\mathrm{CHMs}$ or point cloud in forest inventory are the percentiles (Naesset 2004). A total of 15 height metrics were calculated from each CHM, i.e., maximum, minimum, mean and the height percentiles (h99, h95, h90, h80, ..., h10). For variation and heterogeneity of forest canopy height, we calculated the coefficient of variation (CV) and standard deviation (SD) from each $\mathrm{CHM}$. As mentioned above, the metrics were derived from the vertical distribution of CHMs using a 12-meter radius circle, which corresponds to the size of ground sample plots. Besides, we calculated the canopy cover density parameters and Canopy Volume $\left(C_{\mathrm{vol}}\right)$ which takes into account the horizontal distribution of the canopy structure. We calculated the forest canopy density (cd) by dividing the number of pixels with heights above $2 \mathrm{~m}$ by the total number of pixels within an area of $12 \mathrm{~m}$ radius circular sample plots. Besides, we derived ten types of forest cover density metrics (i.e., $\left.\mathrm{cd}_{1}, \mathrm{~cd}_{2}, \mathrm{~cd}_{3}, \ldots, \mathrm{cd}_{10}\right)$ at sample plots location followed by the methodology adopted by Naesset (2004), Rahlf et al. (2014) and Straub et al. (2013a). The range between the lower canopy height $(>2 \mathrm{~m})$ and maximum height was divided into ten fractions of equal length. Each fraction was considered a threshold and a potential crown region was defined by dividing all $1 \times 1 \mathrm{~m}$ cells covered by height above a certain threshold. The ratio of the crown region area above the pre-specified threshold to the total area of the sample plot was used as an estimate for the canopy cover. The $\mathrm{C}_{\text {vol }}$ was calculated from the $\mathrm{CHM}$, which is the sum of all the heights of $1 \times 1 \mathrm{~m}$ pixels size covering the total circular 12-meter radius sample plot area. The importance of all the above height metrics for the prediction of forest variables was already explained in details by Naesset (2002), Bohlin et al. (2012), Straub et al. (2013a) and Rahlf et al. (2014).

\section{Modeling for predicting ground Lorey's} mean height ( $L M H)$

For predicted $L M H$, we fitted multiple linear regression models between all the explanatory variables extracted above (derived from $\mathrm{CHM}_{\mathrm{SGM}}, \mathrm{CHM}_{\mathrm{eATE}}$ and $\mathrm{CHM}_{\mathrm{ALS}}$ ) and the response variable, which was the $L M H$ of the ground inventory sample plots. The explanatory variables which showed high collinearity and those which were the least significant were dropped out one by one starting with highest p-values (lower than $95 \%$ confident level) until a stage was reached, where removal of explanatory variables had a significant impact on the coefficient of determination $\left(R^{2}\right)$, Root Mean Square Error (RMSE) and relative RMSE (RMSE\%). For estimating $\mathrm{R}^{2}$, RMSE, and RMSE\%, we used a 3 -fold cross-validation process (repeated 3 -times). The data were randomly split into 3 sets. At the first stage, the first set was knocked out as the test set and the remaining two were used as training sets. At the second stage, the middle set was knocked out as the test set and the first and last sets were used as training sets. Similarly, at the third stage, the last set was knocked out as the test set and the first and second sets were used as training sets. $R^{2}, \quad R M S E$, and RMSE\% reported here were the mean of all 3-fold cross validation. The calculation was carried out using the "caret" package (Kuhn 2008) in the statistical software R (R Core Team 2014). RMSE and RMSE\% were calculated using the following equations (eqn. 2 , eqn. 3):

$$
\begin{gathered}
R M S E[m]=\frac{1}{n} \sum_{i=1}^{n}\left(y_{i}-\hat{y}_{i}\right)^{2} \\
R M S E[\%]=\frac{R M S E_{(3-\text { fold } C V)}}{\bar{y}} \cdot 100
\end{gathered}
$$

where $\hat{y}_{i}$ is the predicted values of 3 -fold cross validation using linear regression model, $y_{i}$ is the observed and $\bar{y}$ is the mean values of $L M H$ based on field measurement.

\section{Comparison of image-based CHM \\ $\left(\mathrm{CHM}_{\mathrm{SGM}}\right.$ and $\left.\mathrm{CHM}_{\text {eATE}}\right)$ with pure ALS \\ $\left(\mathrm{CHM}_{\mathrm{ALS}}\right)$}

We calculated the difference maps by subtracting image-based $\mathrm{CHMs}\left(\mathrm{CHM}_{\mathrm{scm}}\right.$ and $\mathrm{CHM}_{\text {eATE }}$ ) of the entire study area from pure ALS $\left(\mathrm{CHM}_{\mathrm{ALS}}\right)$. The difference maps were calculated only for forested areas, while all non-forested areas were excluded using forest and non-forest mask. For normality test of error distribution, we used the Q-Q plots (Fig. 2) and the AndersonDarling's method integrated into the "nortest" package of the R software (Gross \& Ligges 2012). Since the distribution of errors was found to be non-normal (Fig. 2), we derived the accuracy assessment using sample quantiles of the error distribution based on the methodology for DEM accuracy assessment proposed by Höhle \& Höhle (2009) and Hobi \& Ginzler (2012). Using this approach, the median ( $50 \%$ quantile), the normalized median absolute deviation (NMAD) and the $68.3 \%$ and 95\% sample quantiles were calculated from the difference maps using the $\mathrm{R}$ software. The NMAD was calculated according to Höhle \& Höhle (2009) as follows (eqn. 4):

$$
N M A D=1.4826 \cdot \operatorname{median}\left(\left|\Delta h_{j}-m_{\Delta h}\right|\right)
$$

where $\Delta h_{j}$ denotes the individual error $(j=1$, $\ldots, n)$ and $m_{\Delta h}$ is the median of the errors. NMAD is thus proportional to the median of the absolute difference between errors and the median errors.

We also selected a transect line of $1.71 \mathrm{~km}$ 
as shown in Fig. 1 and Fig. 4 for visual interpretation of the trend of $\mathrm{CHM}$. The height values of the CHMs falling along the transect line were extracted and plotted as line graphs (Fig. 5), in order to visually display the trend of correlation between the CHMs.

\section{Results}

Predictions of ground Lorey's mean height (LMH)

The final most explanatory variables derived from $\mathrm{CHM}_{\mathrm{ALS}}$ were the height at $99^{\text {th }}$ percentile and the canopy density (cd), and we achieved $R^{2}=0.83$ and $R M S E=1.93 \mathrm{~m}$ against $L M H$ (Tab. 3). Similarly, we achieved $\mathrm{R}^{2}=0.82$ and RMSE $=2.09 \mathrm{~m}$ by using height at $95^{\text {th }}$ percentiles and canopy density (cd) as explanatory variables derived from $\mathrm{CHM}_{\mathrm{SGM}}$ against $\mathrm{LMH}$. However, for the $\mathrm{CHM}_{\text {eATE}}$, we achieved $\mathrm{R}^{2}=0.55$ and RMSE $=3.22 \mathrm{~m}$ by using height at $90^{\text {th }}$ percentiles, standard derivation (SD) and canopy density $2\left(\mathrm{~cd}_{2}\right)$ metrics as an explanatory variables (Tab. 3 ).

Overall, we did not observed significant differences between the predictive power of the explanatory variables derived from $\mathrm{CHM}_{\mathrm{ALS}}$ and $\mathrm{CHM}_{\mathrm{SCM}}$ for estimating $\mathrm{LMH}$. However, the predictive power of explanatory variables derived from $\mathrm{CHM}_{\mathrm{eATE}}$ was not that accurate as $\mathrm{CHM}_{\mathrm{ALS}}$ and $\mathrm{CHM}_{\mathrm{SGM}}$ for estimating $L M H$ (Tab. 3).

Comparison of image-based Canopy height models ( $\mathrm{CHM}_{\mathrm{SGM}}$ and $\left.\mathrm{CHM}_{\text {eATE }}\right)$ with pure ALS $\left(\mathrm{CHM}_{\mathrm{ALS}}\right)$

A summary of the statistics for the error distribution derived by subtracting $\mathrm{CHM}_{\mathrm{SGM}}$,

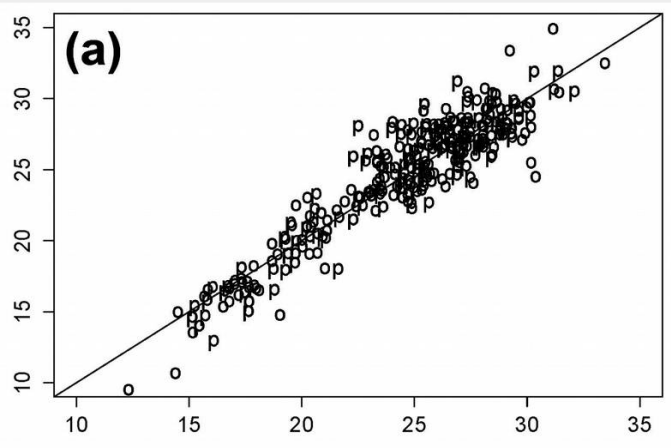

Fig. 3 - Lorey's mean height ( $x$-axis) plotted against the predicted mean height $(y-$ axis). (a): $\mathrm{CHM}_{\mathrm{ALs}}$; (b): $\mathrm{CHM}_{\mathrm{SGM}}$; and (c): CHM $_{\text {eATE}}$.
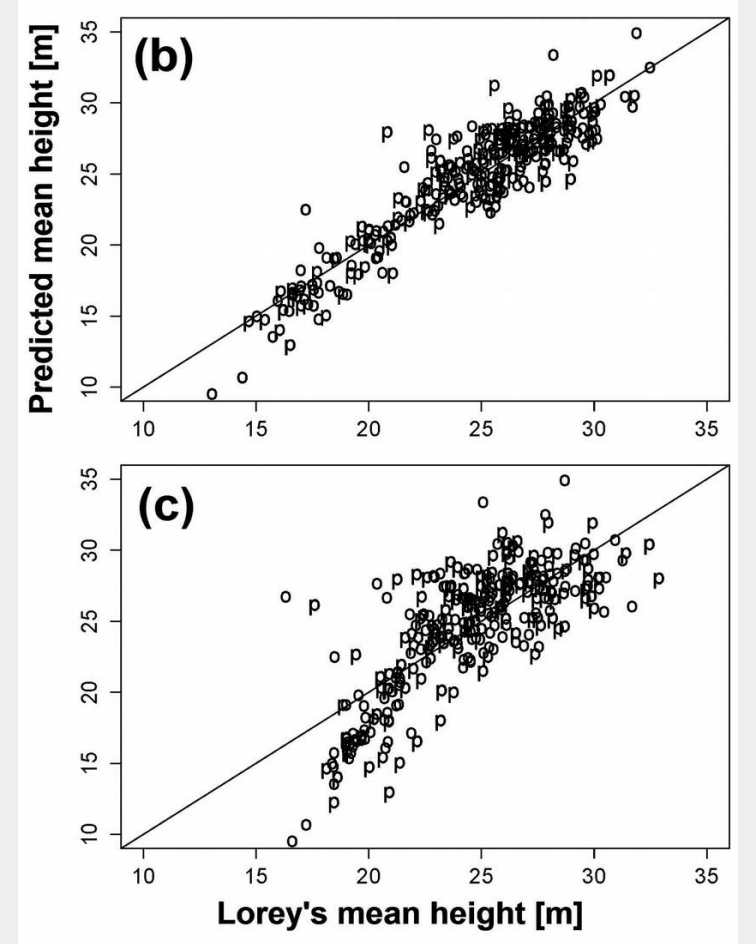

Fig. 4 - Example of the final output maps of the canopy-height models (CHM) obtained in this study, covering a small portion of the whole stud ied area, and including the transect line $(A B C)$ represented in Fig. 1

(a): RGB;

(b): $\mathrm{CHM}_{\mathrm{ALS}}$;

(c) $\mathrm{CHM}_{\mathrm{SGM}}$;

(d) $\mathrm{CHM}_{\mathrm{eATE}}$

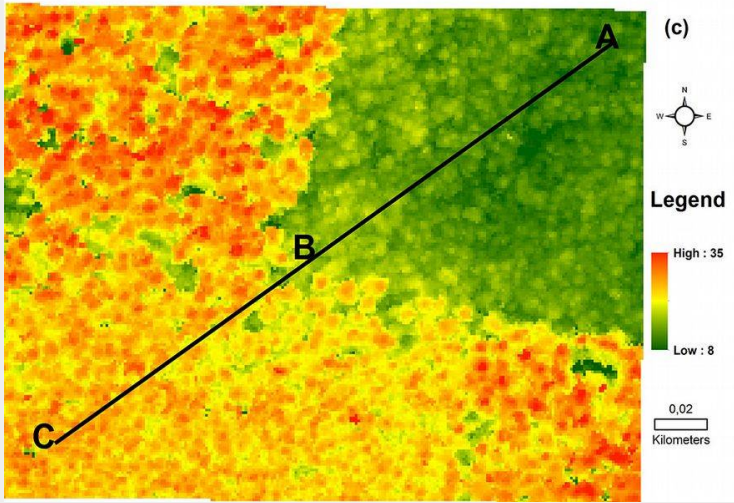

(a)

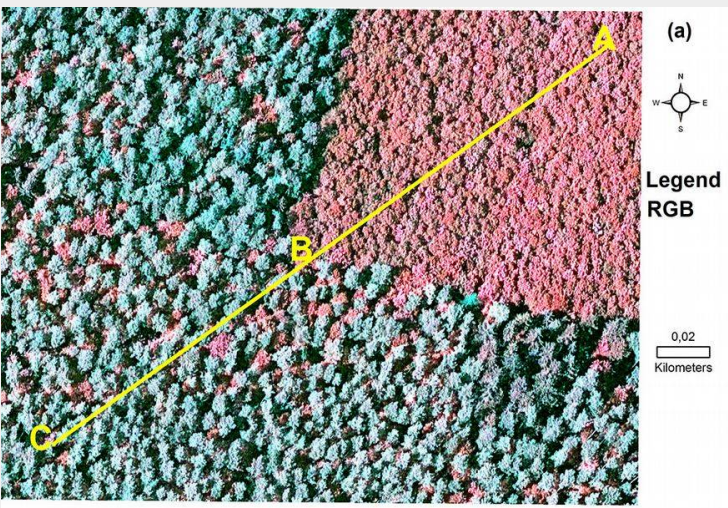

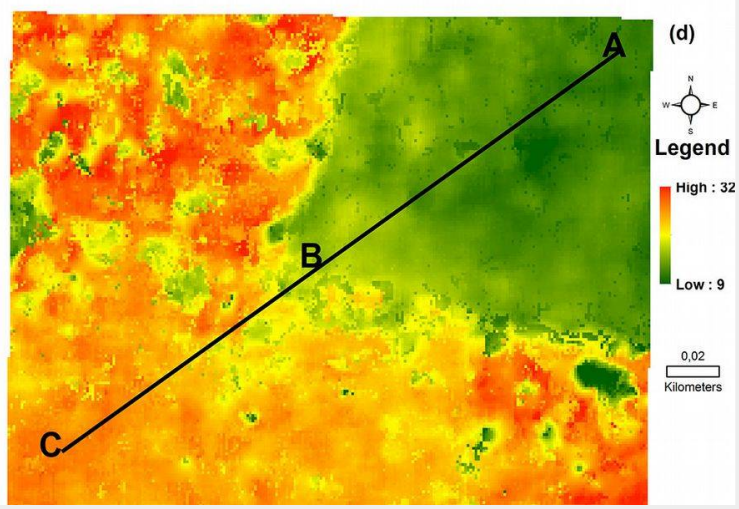

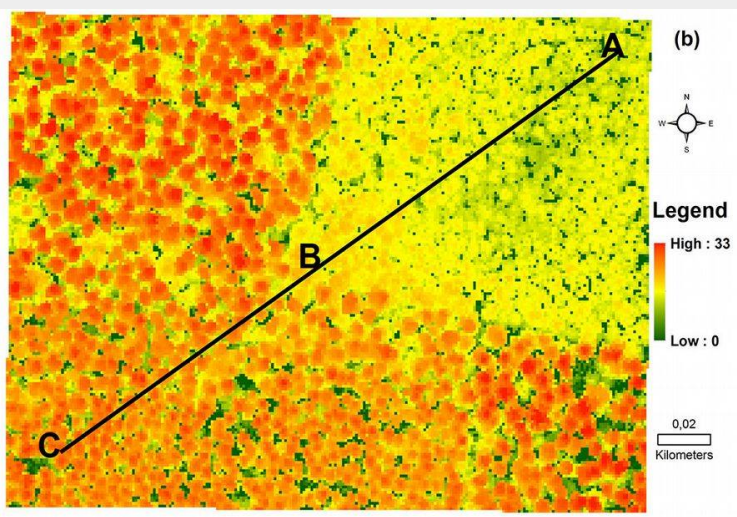

(d) Legend ign: 32 . 


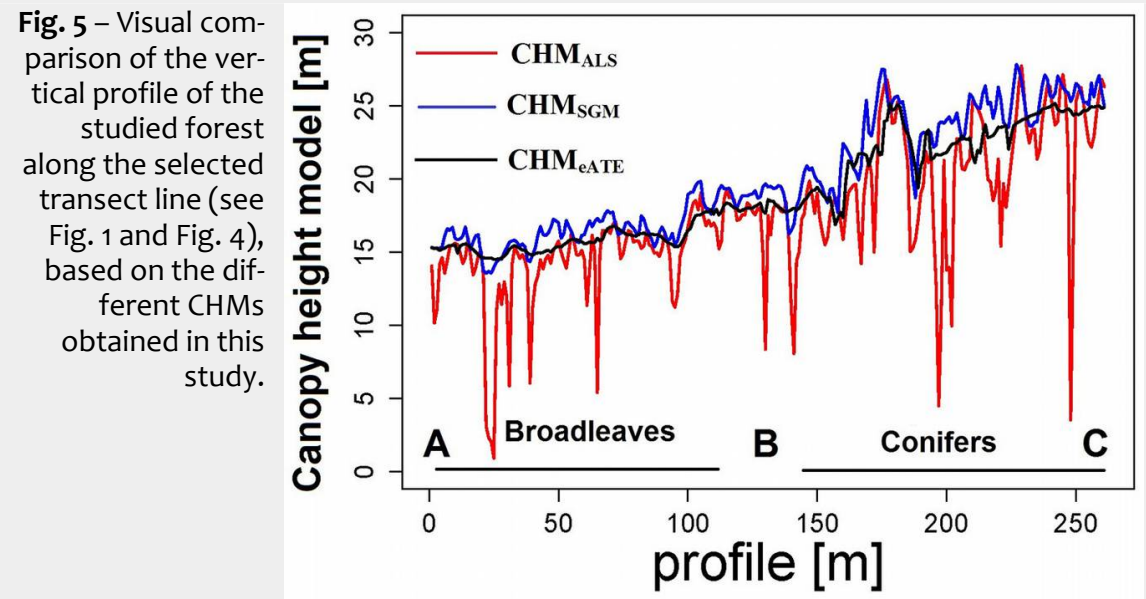

Tab. 3 - Comparison of predicted canopy height vs. ground $L M H$ based on 3-fold cross validation ( $n=296$ plots). $\left(R^{2}\right)$ : coefficients of determination; (Adj. $\left.R^{2}\right)$ : adjusted $R^{2}$; $(* * *): p<0.001,(* *): p<0.01,(*) p<0.05$, and $():. p<0.1$ indicated the level of significance after t-test.

\begin{tabular}{|c|c|c|c|c|c|}
\hline $\begin{array}{l}\text { Canopy height } \\
\text { model (CHM) }\end{array}$ & $\begin{array}{l}\text { Selected } \\
\text { variables }\end{array}$ & Coefficients & $\mathbf{R}^{2}$ & RMSE & RMSE\% \\
\hline \multirow[t]{3}{*}{$\mathrm{CHM}_{\text {ALS }}$} & intercept $^{* *}$ & 4.59 & 0.83 & 1.93 & 7.92 \\
\hline & h99*** & 0.93 & & & \\
\hline & $\mathrm{cd}^{* *}$ & -4.45 & & & \\
\hline \multirow[t]{3}{*}{$\mathrm{CHM}_{\mathrm{SGM}}$} & intercept $^{* * *}$ & 24.46 & 0.82 & 2.09 & 8.54 \\
\hline & h95 & 0.96 & & & \\
\hline & $\mathrm{Cd}^{* * *}$ & -23.88 & & & \\
\hline \multirow[t]{4}{*}{ CHM } & intercept $^{* * *}$ & 35.02 & 0.55 & 3.22 & 13.23 \\
\hline & h90*** & 0.55 & & & \\
\hline & $\operatorname{std}^{* * *}$ & 0.7 & & & \\
\hline & $\mathrm{Cd}_{2}^{* * *}$ & -24.19 & & & \\
\hline
\end{tabular}

Tab. 4 - Comparison of vertical agreement measures of image-based $\mathrm{CHM}\left(\mathrm{CHM}_{\mathrm{sGM}}\right.$ and $\left.\mathrm{CHM}_{\mathrm{eATE}}\right)$ with pure ALS-derived $\mathrm{CHM}\left(\mathrm{CHM}_{\mathrm{ALS}}\right)$.

\begin{tabular}{lcc}
\hline Forested areas & CHM $_{\text {SGM }}$ - CHM $_{\text {ALS }}$ & CHM $_{\text {eATE }}$. CHM \\
\hline Sample size & Summary of the statistics of the error distribution derived \\
& \multicolumn{2}{c}{ from the differences maps } \\
$50 \%$ (median) $[\mathrm{m}]$ & -1.30 & -1.18 \\
NMAD [m] & 0.68 & 1.11 \\
$68.3 \%$ & -0.57 & 0.74 \\
$95 \%$ quantile $[\mathrm{m}]$ & 0.99 & 6.64 \\
\hline
\end{tabular}

$\mathrm{CHM}_{\text {eATE }}$ from $\mathrm{CHM}_{\text {ALS }}$ is shown in Tab. 4. We achieved a median error of $-1.30 \mathrm{~m}$ and $N M A D=0.68 \mathrm{~m}$ from the difference maps derived by subtracting $\mathrm{CHM}_{\mathrm{SGM}}$ from $\mathrm{CHM}_{\mathrm{ALS}}$. However, we achieved a median error of $-1.18 \mathrm{~m}$ and $N M A D=1.11 \mathrm{~m}$ from the difference map obtained by subtracting $\mathrm{CHM}_{\text {eATE }}$ from $\mathrm{CHM}_{\mathrm{ALS}}$. In this case, $\mathrm{CHM}_{\mathrm{SGM}}$ was closer to $\mathrm{CHM}_{\mathrm{ALS}}$ as compared to CHM $_{\text {eAtE }}$ (Tab. 4).

Fig. 4 shows the final output maps of CHMs for a small subset of the study area which includes the transect line for $\mathrm{CHMs}$ comparison.

An example of the vertical profile of the four $\mathrm{CHMs}$ along the transect line depicted in Fig. 4 is shown in Fig. 5, where height values extracted from each CHMs are plotted in the form of line graphs. In general, all the three CHMs show a good agreement of the outer envelops of the forest surface.

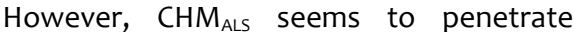
deeper through the small opening of the forest canopy. This suggests that imagebased $\mathrm{CHMs}$ could be limited to the outer envelope of the forest structure and cannot describe in details both the middle layer and the forest ground.

\section{Discussion}

The first objective of our study was to compare the potential of photogrammetric image-based point clouds with ALS-derived data for the assessment of forest heights. The purpose was to find out a viable option for all those countries where stereo aerial photographs are updated on a regular basis, but ALS acquisitions are not that consistent as needed for continuous forest management. For the CHM based on ALS $\left(\mathrm{CHM}_{\mathrm{ALS}}\right)$, we achieved $\mathrm{R}^{2}=0.83$ and RMSE $=7.92 \%$ against $L M H$. Similarly, we achieved $\mathrm{R}^{2}=0.82$ and $\mathrm{RMSE}=8.54 \%$ for the imagebased $\mathrm{CHM}$ using $\mathrm{SGM}\left(\mathrm{CHM}_{\mathrm{SCM}}\right)$ against $L M H$, respectively. However, we achieved $R^{2}=0.55$ and RMSE $=13.23 \%$ for the imagebased CHM using eATE (CHM eATE$)$ with $L M H$, which is not that accurate as $\mathrm{CHM}_{\mathrm{ALS}}$ and $\mathrm{CHM}_{\mathrm{SCM}}$. White et al. (2015b) used SGM and compared the potential of ALS and image-

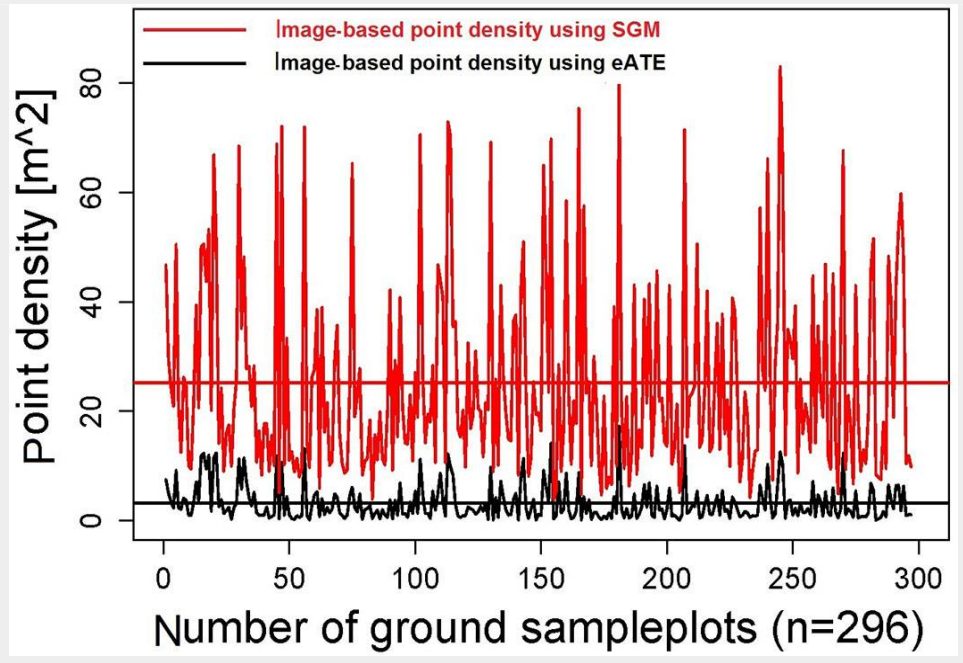

Fig. 6 - Comparison of point density per square meter derived from SGM and eATE. The red graph represents mean point density $\left[\mathrm{m}^{2}\right]$ derived from SGM at sample plots locations, while the straight red line represents the mean point density over all sample plots $(n=296)$. The black line graph represents the mean point density $\left[\mathrm{m}^{2}\right]$ derived from eATE at sample plots locations, while the straight black line represents the mean point density over all sample plots $(n=296)$. 
based point cloud metrics for estimating $\mathrm{LMH}$ at the plot level. They obtained RMSE $=8.96 \%$ for ALS and $14 \%$ for image-based point clouds with $L M H$., i.e., a lower accuracy as compared with that obtained in this study. Järnstedt et al. (2012) used the NGATE module of the SOCET SET for point clouds generation and compared the potential of ALS and image-based point clouds for estimating the tree mean height at the plot level. They obtained an RMSE = $18.61 \%$ for ALS and $28.23 \%$ for image-based point clouds, which is also higher than our results based on SGM. The error distribution in the form of quantiles derived from the differences maps (Tab. 4) also indicates that the image-based $\mathrm{CHM}$ using SGM $\left(\mathrm{CHM}_{\mathrm{SGM}}\right)$ is closer to ALS CHM (CHM $\left.\mathrm{ALS}\right)$ than the image-based point clouds using eATE (CHM

The second objective was to compare the performance of two image-matching algorithms (SGM and eATE) for estimating the canopy height. It is evident that SGM gives more accurate results than EATE by both evaluating the metrics derived from imagebased CHM for predicting $\mathrm{LMH}$ and comparing image-based $\mathrm{CHM}\left(\mathrm{CHM}_{\mathrm{SCM}}\right.$ and $\left.\mathrm{CHM}_{\text {eATE }}\right)$ with ALS-derived CHM ( $\left.\mathrm{CHM}_{\text {ALS }}\right)$. We obtained reasonably accurate estimates of tree heights by using SGM image matching point clouds algorithm then eATE in combination with ALS-derived DTM. One of the reasons of the higher accuracy of SGM might be the production of point clouds. We achieved a mean point density of 25 points $\mathrm{m}^{-2}$ by using SGM and 3.19 points $\mathrm{m}^{-2}$ using eATE at sample plots location (Fig. 6). This demonstrates that point clouds based on the SGM image-matching algorithm better represent the tree structure, including the tree tops and the surrounding crown area, as compared to eATE point clouds. This difference can also be noticed from Fig. 4, where eATE-based CHM looks smoother and less coarse than SGM-based CHM. According to Gobakken \& Naesset (2008) and Magnusson (2006), the higher is the point density, the higher will be the accuracy of forest attribute estimation. However, they compared different ALS point clouds density, while we examined first-time image-based point clouds density for determining forest heights.

\section{Conclusions}

Our findings show that forest height information can be accurately extracted from image-based point clouds in all those forest areas where highly accurate DTMs obtained from ALS campaigns are available. The quality of such height information is comparable to ALS based product, which is a promising outcome. Further, our results confirmed that the SGM algorithm performs better than the eATE for the estimation of tree height.

ALS is the most accurate option for estimating forest structure variables and is currently used for forest management purpose in many Nordic countries. However, in many other countries, ALS data are not regularly updated as digital stereo aerial photographs, due to its high cost. So the combined approach of using image-based point clouds and historical ALS-derived DTM developed in this study offer a viable and cost-effective option to forest community for estimating height-related forest structural parameters, and can be useful for all those countries where stereo aerial photographs are updated at a regular period in the presence of pre-existing historical ALS-derived DTM.

\section{Acknowledgments}

The authors are thankful to the Shaheed Benazir Bhutto University, Sheringal Dir Upper and Higher Education Commission (HEC) of Pakistan for awarding Mr. Sami Ullah a PhD scholarship, which enabled this research work. Furthermore, we are thankful to European Commission for the financial support of the project Delivery of sustainable supply of non-food biomass to support a "resource-efficient" Bioeconomy in Europe (S2BIOM). This research work is closely linked and was partly funded by S2Biom is co-funded by the European Commission in the $7^{\text {th }}$ Framework Programme (Project No. FP7-608622, Project web site: http://www.s2biom.eu/en/). The authors are also grateful to Dr. Gerald Kändler, Forest Research Institute, Baden-Württemberg (FVA) for the provision of aerial photographs, field inventory data and related possibilities to Sami Ullah at FVA.

\section{References}

Bohlin J, Wallerman J, Fransson JE (2012). Forest variable estimation using photogrammetric matching of digital aerial images in combination with a high-resolution DEM. Scandinavian Journal of Forest Research 27 (7): 692-699. doi: 10.1080/02827581.2012.686625

Brandtberg T (1999). Automatic individual tree based analysis of high spatial resolution aerial images on naturally regenerated boreal forests. Canadian Journal of Forest Research 29 (10): 1464-1478. - doi: 10.1139/x99-150

Dees M, Straub C, Koch B (2012). Can biodiversity study benefit from information on the vertical structure of forests? Utility of LiDAR remote sensing. Current Science (Bangalore) 102 (8): 1181-1187. [online] URL: http://www.indiaenvi ronmentportal.org.in/files/file/biodiversitystudy .pdf

ERDAS_IMAGINE (2012). LPS eATE. Hexagon Geospatial, Madison, AL, USA. [online] URL: http://hexagongeospatial.fluidtopics.net/book\# !book;uri=5d68e1db557af5bab494d96c7f8e1a9 d

Fieber KD, Davenport IJ, Tanase MA, Ferryman JM, Gurney RJ, Becerra VM, Walker JP, Hacker JM (2015). Validation of canopy height profile methodology for small-footprint full-waveform airborne LiDAR data in a discontinuous canopy environment. ISPRS Journal of Photogrammetry and Remote Sensing 104: 144-157. - doi: 10.1016/j.isprsjprs.2015.03.001

Gehrke S, Morin K, Downey M, Boehrer N, Fuchs $T$ (2010). Semi-global matching: an alternative to LIDAR for DSM generation. In: Proceedings of the "2010 Canadian Geomatics Conference and Symposium of Commission I (vol. 2)". ISPR, Canada, pp. 6. [online] URL: http://pdfs.se manticscholar.org/5b36/5279c5ac32a3dc158b57 a37f6827011b1be4.pdf

Gobakken T, Naesset E (2008). Assessing effects of laser point density, ground sampling intensity, and field sample plot size on biophysical stand properties derived from airborne laser scanner data. Canadian Journal of Forest Research 38 (5): 1095-1109. - doi: 10.1139/X07-219

Gross J, Ligges U (2012). Nortest: tests for normality. $\mathrm{R}$ package version 1: 0-2, $\mathrm{R}$ Foundation for Statistics Computing, Vienna, Austria. [online] URL: http://CRAN.R-project.org/packa ge=nortest

Hirschmuller H (2005). Accurate and efficient stereo processing by semi-global matching and mutual information. In: Proceedings of the IEEE Computer Society Conference "Computer Vision and Pattern Recognition 2005 (CVPR 2005)". IEEE, vol. 2, pp. 807-814. - doi: 10.1109/ CVPR.2005.56

Hirschmüller H (2008). Stereo processing by semiglobal matching and mutual information., IEEE Transactions on Pattern Analysis and Machine Intelligence 30 (2): 328-341. - doi: 10.1109/ TPAMI.2007.1166

Hobi ML, Ginzler C (2012). Accuracy assessment of digital surface models based on WorldView-2 and ADS80 stereo remote sensing data. Sensors 12 (5): 6347-6368. - doi: 10.3390/s120506 347

Hyyppä J, Inkinen M (1999). Detecting and estimating attributes for single trees using laser scanner. The Photogrammetric Journal of Finland 16 (2): 27-42.

Hyyppä J, Hyyppä H, Leckie D, Gougeon F, Yu X, Maltamo M (2008). Review of methods of small footprint airborne laser scanning for extracting forest inventory data in boreal forests. International Journal of Remote Sensing 29 (5): 1339-1366. - doi: 10.1080/014311607 01736489

Höhle J, Höhle M (2009). Accuracy assessment of digital elevation models by means of robust statistical methods. ISPRS Journal of Photogrammetry and Remote Sensing 64 (4): 398406. - doi: 10.1016/j.isprsjprs.2009.02.003 Jan J-F (2005). Comparison of forest canopy height derived using LIDAR data and aerial photos. Taiwan Journal for Science 20: 13-27. [online] URL: http://citeseerx.ist.psu.edu/view doc/download?doi=10.1.1.498.9701\&rep=rep1\& type $=p d f$

Järnstedt J, Pekkarinen A, Tuominen S, Ginzler C, Holopainen M, Viitala R (2012). Forest variable estimation using a high-resolution digital surface model. ISPRS Journal of Photogrammetry and Remote Sensing 74: 78-84. - doi: 10.1016/ j.isprsjprs.2012.08.006

Koch B, Heyder U, Weinacker H (2006). Detection of individual tree crowns in airborne lidar data. Photogrammetric Engineering and Remote Sensing 72 (4): 357-363. - doi: 10.14358/ PERS.72.4.357

Kublin E (2003). Einheitliche Beschreibung der Schaftform-Methoden und Programme-BDATPro [A uniform description of stem profiles methods and programs - BDATPro]. European 
Journal of Forest Research 122 (3): 183-200. [in German]

Kuhn M (2008). The caret package. R Foundation for Statistical Computing, Vienna, Austria. [online] URL: http://download.nextag.com/cran /web/packages/caret/caret.pdf

Lorey T (1878). Die mittlere Bestandeshöhe [The average canopy height]. Allgemeine Forst-und Jagdzeitung 54: 149-155. [in German]

Magnusson M (2006). Evaluation of remote sensing techniques for estimation of forest variables at stand level. Doctoral thesis, Swedish University of Agricultural Sciences, Umeå, Sweden, pp. 38. [online] URL: http://pub.epsilon. slu.se/1211/

Maltamo M, Packalen P (2014). Species-specific management inventory in Finland. In: "Forestry Applications of Airborne Laser Scanning". Springer Science+Business Media, Dordrecht, Netherlands, pp. 241-252. - doi: 10.1007/978-94017-8663-8_12

Naesset $E$ (2002). Predicting forest stand characteristics with airborne scanning laser using a practical two-stage procedure and field data. Remote Sensing of Environment 80 (1): 88-99. doi: 10.1016/S0034-4257(01)00290-5

Naesset E, Okland T (2002). Estimating tree height and tree crown properties using airborne scanning laser in a boreal nature reserve. Remote Sensing of Environment 79 (1): 105-115. - doi: 10.1016/S0034-4257(01)00243-7

Naesset E (2004). Effects of different flying altitudes on biophysical stand properties estimated from canopy height and density measured with a small-footprint airborne scanning laser. Remote Sensing of Environment 91 (2): 243-255. - doi: 10.1016/j.rse.2004.03.009

Naesset E (2007). Airborne laser scanning as a method in operational forest inventory: status of accuracy assessments accomplished in Scandinavia. Scandinavian Journal of Forest Research 22 (5): 433-442. - doi: 10.1080/028275807 01672147

Naesset E (2014). Area-based inventory in Norway-from innovation to an operational reality. In: "Forestry Applications of Airborne Laser Scanning". Springer Science+Business Media, Dordrecht, Netherlands, pp. 215-240. - doi: 10.1007/978-94-017-8663-8_11

Nelson R, Krabill W, MacLean G (1984). Determining forest canopy characteristics using airborne laser data. Remote Sensing of Environment 15 (3): 201-212. - doi: 10.1016/0034-4257 (84) $90031-2$

Nilsson M (1996). Estimation of tree heights and stand volume using an airborne lidar system. Remote Sensing of Environment 56 (1): 1-7. doi: 10.1016/0034-4257(95)00224-3

Ota T, Ogawa M, Shimizu K, Kajisa T, Mizoue N, Yoshida S, Takao G, Hirata Y, Furuya N, Sano T, Sokh H, Ma V, Ito E, Toriyama J, Monda Y, Saito H, Kiyono Y, Chann S, Ket N (2015). Aboveground biomass estimation using structure from motion approach with aerial photographs in a seasonal tropical forest. Forests 6 (11): 3882-3898. - doi: 10.3390/f6113882

Packalén P, Pitkänen J, Maltamo M (2008). Comparison of individual tree detection and canopy height distribution approaches: a case study in Finland. In: Proceedings of the Conference "SilviLaser 2008". Edinburgh (UK) 17-19 Sept 2008, pp 22-29. [online] URL: http://geography. swan.ac.uk/silvilaser/papers/oral_papers/Forest ryApplications\&Inventory/Packalen.pdf

Pitkänen J, Maltamo M, Hyyppä J, Yu X (2004). Adaptive methods for individual tree detection on airborne laser based canopy height model. International Archives of Photogrammetry, Remote Sensing and Spatial Information Sciences 36 (8): 187-191. [online] URL: http://www.isprs. org/proceedings/XXXVI/8-W2/PITKAENEN.pdf

R Core Team (2014). R: a language and environment for statistical computing. R Foundation for Statistical Computing. Vienna, Austria. [online] URL: http://www.r-project.org

Rahlf J, Breidenbach J, Solberg S, Naesset E, Astrup R (2014). Comparison of four types of 3D data for timber volume estimation. Remote Sensing of Environment 155: 325-333. - doi: 10.1016/j.rse.2014.08.036

Rothermel M, Haala N (2011). Potential of dense matching for the generation of high quality digital elevation models. In: Proceedings of the "ISPRS Hannover Workshop 2011: High-Resolution Earth Imaging for Geospatial Information". ISPRS - International Archives of the Photogrammetry, Remote Sensing and Spatial Information Sciences XXXVIII-4/W19: 271-276. - doi: 10.5194/isprsarchives-XXXVIII-4-W19-271-2011

Rönnholm P, Hyyppä J, Hyyppä H, Haggrén H, Yu $X$, Kaartinen H (2004). Calibration of laser-derived tree height estimates by means of photogrammetric techniques. Scandinavian Journal of Forest Research 19 (6): 524-528. - doi: 10.1080/02827580410019436

Scharstein D, Szeliski R (2002). A taxonomy and evaluation of dense two-frame stereo correspondence algorithms. International Journal of Computer Vision 47(1-3): 7-42. [online] URL: http://ieeexplore.ieee.org/document/988771/

St-Onge B, Jumelet J, Cobello M, Véga C (2004). Measuring individual tree height using a combination of stereophotogrammetry and lidar. Canadian Journal of Forest Research 34 (10): 2122-2130. - doi: 10.1139/x04-093

Stepper C, Straub C, Pretzsch H (2015). Assessing height changes in a highly structured forest using regularly acquired aerial image data. Forestry 88 (3): 304-316. - doi: 10.1093/forestry/ cpu050

Straub C, Stepper C, Seitz R, Waser LT (2013a). Potential of UltraCamX stereo images for estimating timber volume and basal area at the plot level in mixed European forests. Canadian Journal of Forest Research 43 (8): 731-741. - doi: 10.1139/cjfr-2013-0125
Straub C, Tian J, Seitz R, Reinartz P (2013b). Assessment of Cartosat-1 and WorldView-2 stereo imagery in combination with a LiDARDTM for timber volume estimation in a highly structured forest in Germany. Forestry 86 (4): 463-473. - doi: 10.1093/forestry/cpto17 Tesfamichael S, Van Aardt J, Ahmed F (2010). Estimating plot-level tree height and volume of Eucalyptus grandis plantations using small-footprint, discrete return lidar data. Progress in Physical Geography 34 (4): 515-540. - doi: 10.1177/0309133310365596

Véga C, St-Onge B (2008). Height growth reconstruction of a boreal forest canopy over a period of 58 years using a combination of photogrammetric and lidar models. Remote Sensing of Environment 112 (4): 1784-1794. - doi: 10.1016/j.rse.2007.09.002

Weinacker H, Koch B, Weinacker R (2004). TREESVIS: a software system for simultaneous ED-real-time visualisation of DTM, DSM, laser raw data, multispectral data, simple tree and building models. International Archives of Photogrammetry, Remote Sensing and Spatial Information Sciences 36: 90-95. [online] URL: http://www.isprs.org/proceedings/xxxvi/8-w2/ weinacker2.pdf

White JC, Wulder MA, Vastaranta M, Coops NC, Pitt D, Woods M (2013). The utility of imagebased point clouds for forest inventory: A comparison with airborne laser scanning. Forests 4 (3): 518-536. - doi: 10.3390/f4030518

White JC, Arnett JT, Wulder MA, Tompalski P, Coops NC (2015a). Evaluating the impact of leaf-on and leaf-off airborne laser scanning data on the estimation of forest inventory attributes with the area-based approach. Canadian Journal of Forest Research 45 (11): 14981513. - doi: 10.1139/cjfr-2015-0192

White JC, Stepper C, Tompalski P, Coops NC, Wulder MA (2015b). Comparing ALS and imagebased point cloud metrics and modelled forest inventory attributes in a complex coastal forest environment. Forests 6 (10): 3704-3732. - doi: 10.3390/f6103704

Yamamoto K, Takahashi T, Miyachi Y, Kondo N, Morita S, Nakao M, Shibayama T, Takaichi Y, Tsuzuku M, Murate N (2017). Estimation of mean tree height using small-footprint airborne LiDAR without a digital terrain model. Journal of Forest Research 16 (6): 425-431. - doi: 10.1007/s10310-010-0234-5

Yu X, Hyyppä J, Kaartinen H, Maltamo M (2004). Automatic detection of harvested trees and determination of forest growth using airborne laser scanning. Remote Sensing of Environment 90 (4): 451-462. - doi: 10.1016/j.rse.2004. 02.001

Zielewska-Büttner $\mathrm{K}$, Adler $\mathrm{P}$, Ehmann $\mathrm{M}$, Braunisch $\vee$ (2016). Automated detection of forest gaps in spruce dominated stands using canopy height models derived from stereo aerial imagery. Remote Sensing 8 (3): 175. 